\title{
Birth synchrony in greater spear-nosed bats (Phyllostomus hastatus)
}

\author{
T. A. Porter* and G. S. Wilkinson \\ Department of Biology, University of Maryland, College Park, MD 20742, U.S.A. \\ (Accepted 2 March 2000)
}

\begin{abstract}
For many animals, strategies for optimally timing reproduction involve monitoring not only the physical environment, but also the social context. To explore the potential for social factors to modulate reproductive seasonality, the influence of social and environmental cues on birth timing was examined in greater spear-nosed bats Phyllostomus hastatus. Births were observed or dated from pup growth curves in three caves on Trinidad, West Indies, over 4 years. Nearly $40 \%$ of the variability in birth dates could be explained by environmental factors because birth dates differed significantly between years and showed consistent differences between locations that receive differing rainfall amounts. Nevertheless, the timing of births within caves and in captivity indicated that social cues also affect the timing and synchrony of births within female social groups. Within each cave, social groups differed significantly in mean birth dates. Two groups of greater spear-nosed bats brought into captivity and maintained without seasonal cues initially exhibited less birth synchrony than wild groups, but birth synchrony did not decline over 3 subsequent years. Further evidence for the influence of social cues on reproductive timing came from four females that were transferred between the captive groups and then gave birth in synchrony with their new group and out of schedule with their original group. Social cues influencing reproductive timing are unlikely to be volatile chemicals or other passively transferred cues, given that frequent prolonged physical contact did not increase birth synchrony between adjacent wild groups. Cues are more probably transferred actively between female group members, perhaps by grooming, or through mating with one attendant male.
\end{abstract}

Key words: Chiroptera, Phyllostomidae, reproductive synchrony, seasonality

\section{INTRODUCTION}

With a few exceptions, such as common vampire bats Desmodus rotundus (Wimsatt \& Trapido, 1952), most bat species studied to date display strong seasonality and synchrony in their reproductive cycles such that lactation coincides with maximum food availability (Heideman, 1995, 2000). Environmental cues used by bats to entrain reproductive cycles include photoperiod, rainfall, food abundance, and temperature (Bradbury, 1979; Racey, 1982; Cumming \& Bernard, 1997; Heideman, 2000; Racey \& Entwistle, 2000). The role of social cues in synchronizing reproduction in bats, however, has received little study.

Greater spear-nosed bats Phyllostomus hastatus present an ideal system in which to explore the possible influences of environmental and social conditions on reproductive timing. Females form stable social groups

*All correspondence to: Dr Teresa A. Porter.

E-mail: tp35@umail.umd.edu of eight to 40 individuals who are not closely related (McCracken \& Bradbury, 1981; McCracken, 1987). The females spend most of the day pressed against groupmates in the same solution depression in a cave ceiling, year after year, thereby affording considerable opportunity for the exchange of chemical or other social cues. One adult male attends each group of females yearround and repels other males. Although two birth peaks (April and October) have been reported for greater spear-nosed bat populations in Colombia and Venezuela, births outside late March to early May are rare on Trinidad and in Nicaragua and Panama (James, 1977; Wilson, 1979; McCracken \& Bradbury, 1981). In addition to a relatively short birth season in Trinidad, McCracken \& Bradbury (1981) found temporal clustering of births within caves. Furthermore, within each cave, the similarity among pup ages seemed to be greater within than across social groups. These authors suggested that birth clustering might be attributable in part to common seasonal cues from local environments. Members of each group forage in nearby or overlapping 
areas that are separate from those of other groups (McCracken \& Bradbury, 1981; Wilkinson \& Boughman, 1998). Some individuals within groups continue to use the same foraging areas in successive years (McCracken \& Bradbury, 1981). McCracken \& Bradbury (1981) also speculated that social interactions might affect reproductive timing.

This paper examines both environmental and social influences on reproductive timing in greater spear-nosed bats. We quantify birth synchrony among greater spearnosed bats in three caves on the island of Trinidad across four different birth seasons and compare birth dates between caves in sites that differ in rainfall. Systematic differences in birth dates between caves would provide evidence for environmental effects on reproductive timing. Greater synchrony within than between social groups in a cave would be consistent with social cues regulating synchrony. By comparing birthing patterns between pairs of groups that habitually roost close enough for females regularly to contact members of the other group, we assess the potential for volatile chemical cues to influence reproductive timing. In addition, we compare the synchrony of births in two captive groups to that of wild groups, and in females transferred between two captive groups, to determine if birth synchrony is achieved and maintained in the absence of seasonal cues. Maintenance of reproductive synchrony in captivity and achievement of birth synchrony by females introduced to a new group would provide additional evidence for social regulation of reproductive timing in this species.

\section{METHOD}

\section{Field captures and observations}

To assess the effect of cave location on birth synchrony we captured greater spear-nosed bat pups in 3 caves (Caura, Guanapo, and Tamana) on Trinidad, West Indies. Between 1975 and 1997 annual rainfall averaged $230 \mathrm{~cm}$ at Caura Cave $\left(10^{\circ} 42^{\prime} \mathrm{N}, 61^{\circ} 22^{\prime} \mathrm{W}\right)$ and $260 \mathrm{~cm}$ at both Tamana Cave $\left(10^{\circ} 21^{\prime} \mathrm{N}, 61^{\circ} 11^{\prime} \mathrm{W}\right)$ and Guanapo Cave $\left(10^{\circ} 41^{\prime} \mathrm{N}, 61^{\circ} 16^{\prime} \mathrm{W}\right)$ (Singh, 1997). Between 21 and 30 April 1990 and between 14 and 30 April 1991, we captured each of 11 groups ( 3 in Caura, 5 in Guanapo, and 3 in Tamana) at the end of the birthing period. We caught each group by lifting a plastic-sided, wirebottomed basket up to the cave ceiling with an attached pole and brushing the bats from their solution depression into the basket with a paddle or bent coat hanger, attached to another pole. A uniquely numbered stainless steel band (Monel, 8 gauge, National Band and Tag Co., Newport, KY) was applied to the forearm if the bat had not been captured in previous years (cf. Wilkinson \& Boughman, 1998).

In 1995 and 1997 data collection was limited to the most densely populated cave, Guanapo, to quantify more precisely the degree of birth synchrony within groups. From 6 April to 2 May in 1995 and from 3 to 29
April and on 2 June in 1997, we monitored 27 reproductive groups daily for the appearance of new pups, counting the number of pups each group contained and noting the appearance of neonates. For all pups born in 1990, 1991, before and after our census period in 1995 and before our census period in 1997, birth dates were estimated from pup forearm lengths using a linear regression. The regression predicted $96 \%$ of the variation in age for pups $<35$ days old (Stern \& Kunz, 1998). All pups were measured within 35 days of their estimated birth date. We assumed that pups with an umbilicus still attached had been born in the previous 24 h. For known birth dates in 1995 and 1997, the correlation between the actual and estimated birth dates was $r=0.93$ (d.f. $=85, P<0.001$ ).

Only $6(1.9 \%)$ of 314 females, from 4 different groups, were still pregnant at the end of the April census period in 1997. Of these, the pregnant female with the lowest body mass ( $80.8 \mathrm{~g}$ ) was observed on 2 June 1997 nursing a pup which lacked fur and umbilicus, indicating it was between 1 and 7 days old. All other pups in the cave on that day had fur and dark skin, indicating they were at least 14 days old (T. A. Porter, pers. obs.). Two of the pregnant females weighed $>90 \mathrm{~g}(92 \mathrm{~g}$ and $94.8 \mathrm{~g})$ on 29 April, indicating that parturition would occur within 12 days (A. A. Stern \& T. A. Porter, pers. obs.). From this evidence we assigned the 6 pregnant females their latest possible birth dates to provide a conservative estimate of within-group synchrony.

\section{Captive observations}

To determine whether environmental cues are necessary for the maintenance of birth synchrony in groups of greater spear-nosed bats, we examined the temporal patterns of parturition in 2 groups of bats that had been captured from Tamana Cave, Trinidad, and housed at the National Zoological Park, Washington, DC since January 1993. Group 1 contained 11 adult females and the resident adult male. Group 2 consisted of 12 adult females and, because their original resident male escaped capture, an adult male residing in an all-male group in the same cave.

Each group was kept in a separate indoor enclosure with a floor area of $6 \times 4 \mathrm{~m}$ and a wire mesh ceiling $4 \mathrm{~m}$ above the floor. Each enclosure contained 3 feeding stations and 2 roost boxes, all suspended $2 \mathrm{~m}$ off the floor. The plywood roost boxes were $60 \times 60 \times 45 \mathrm{~cm}$, closed on the sides and top and open on the bottom, and lined with plastic hardware cloth on the ceiling and 1 inside wall. In each room, the bats spent nearly all their time clustered together in 1 side of 1 roostbox, with little change in the group position between 1993 and 1997.

Both groups experienced a $12: 12 \mathrm{~h}$ reversed light : dark cycle for the first year, after which the keepers switched to a $3: 21 \mathrm{~h}$ cycle to mimic more closely dark conditions inside caves. After the initial 10 weeks of captivity, the bats were fed melon slices, canned dog 
food (Alpo, Friskies Petcare Co. Inc, Glendale, CA), primate diet (ZuPreem Marmoset Diet, Premium Nutritional Products, Inc., Mission, KS) and dead mice. Other than the substitution of a different fruit type on occasion, neither the content nor amount per bat changed over time. Water was provided ad libitum.

The relative humidity was kept at $65 \pm 5 \%$ in both rooms. The maximum and minimum daily temperatures were measured inside the roost, near the open, lower edge. We attempted to keep the ambient temperature in both rooms close to cave temperatures $\left(c .28^{\circ} \mathrm{C}\right.$; pers. obs.). However, the mean daily temperature of the room inhabited by group $1\left(\right.$ mean $\left.\pm \mathrm{SE}=29.68 \pm 0.06{ }^{\circ} \mathrm{C}\right)$ was $2{ }^{\circ} \mathrm{C}$ warmer, on average, than the room housing group $2\left(27.74 \pm 0.04{ }^{\circ} \mathrm{C}\right)$.

We monitored both groups at least once daily and recorded births between 1994 and 1997. Group 1 produced offspring in 1994, 1995, and 1996, after which the reproductive male underwent a vasectomy for reasons of colony management. Group 2 failed to produce any offspring in 1994; we analysed their parturition dates for 1995, 1996, and 1997, after which the group 2 male was vasectomized. On 6 February 1996, 5 captive-born females from group 1 were transferred to group 2 (Boughman, 1998). This subgroup contained 31 -yearold, pre-reproductive females and 2 2-year-old pregnant females; female $P$. hastatus do not give birth in their first year (McCracken \& Bradbury, 1981; pers. obs.). We compared parturition dates in the subgroup the next year, when all 5 bats were of reproductive age, with those of their natal and new groups to examine the influence of group membership on birth timing.

\section{Statistics}

To compare birth dates between 1990 and 1991 across caves and among groups within caves, we performed a nested, mixed model analysis of variance (ANOVA). Significantly less variation in birth dates within than between groups was interpreted as within-group birth synchrony. Fisher's protected least significant difference (PLSD) post-hoc test was used to make pairwise comparisons among the 3 caves (SuperANOVA, v. 1.11, Abacus Concepts, Inc.). Because we assumed group and cave to be random effects, we estimated the fraction of variation explained by these factors using the VARCOMP procedure (SAS, v. 6.12). To determine if groups within a cave gave birth in similar order across years, we first corrected for differences in the cave birth dates by subtracting from each birth date the mean for the cave that year and then computed the correlation between the 1990 and 1991 mean group birth dates.

In 1995 and 19974 groups with 3 or fewer births were discarded because these groups either dispersed or consisted primarily of first-year females. All other groups had 8 or more pups. We obtained data for 16 groups in both 1995 and 1997; 4 additional groups in each year were not represented in the other year. As in the 1990-91 analysis, some, but not all, of the females present in a group in 1 year were also present the other year. However, because we censussed the pups in the absence of their mothers, we do not know which females gave birth in both years. Therefore, we performed a separate 1-way ANOVA for each year to determine whether births were synchronous within groups. We used a 2way ANOVA (year $\times$ group) to determine if parturition dates differed across years. For the 16 overlapping groups, we computed the correlation between the mean birth dates in 1995 and 1997 to determine if groups from 1 cave gave birth in similar order across years.

In Guanapo Cave in 1995, at least 8 births per group occurred in 4 pairs of groups in close proximity. A randomization model was used to test whether the births were more synchronous between these pairs than between all non-adjacent pairs of groups in the cave. We sampled without replacement 4 pairs of groups at random from the 190 possible pairs of 20 groups, averaged the between-group disparity in mean birth date, and repeated this process 1000 times to generate a null distribution of between-group differences in mean birth dates. We then compared the mean of the observed between-group differences to this null distribution to determine if pairs in close proximity differ less in mean birth date than would be expected by chance.

To assess whether the birth dates at the National Zoo were more variable than those in the wild, we compared the standard deviations of both captive groups each year to standard deviations of birth dates in wild groups. We calculated $Z$-scores of the captive birth standard deviations using the distribution of Guanapo 1995 birth dates as the null distribution. This distribution did not differ significantly from normality (Kolmogorov-Smirnov test: $D_{K}=0.041, P>0.20$ ). We used this year because the methods for determining birth dates were similar and because both captive groups gave birth in 1995 (but not in 1997). Because in group 1, the male had a vasectomy after the 1996 births, and therefore the females did not conceive again, we compared the 1997 birth dates of the transferred females to those of their natal group (1) in 1996 and of the new group (2) in 1997 using unpaired $t$-tests. We report mean birth dates \pm standard error to describe parturition patterns.

\section{RESULTS}

\section{Cave and group synchrony in the wild}

In 1990 and 1991, 98.3\% of the 235 recorded greater spear-nosed bat births occurred in the 30-day period between 1 and 30 April. The number of births per group ranged from four to 22 (mean $=11.1 \pm 1.1$ ) births per year. Of the mothers caught in 1990, 52\% gave birth again in the same group in 1991. Despite the strong seasonality of births across the island each year, mean parturition date differed significantly between years, among caves, and among groups within each cave (Table 1). Pups were born significantly later in 1990 


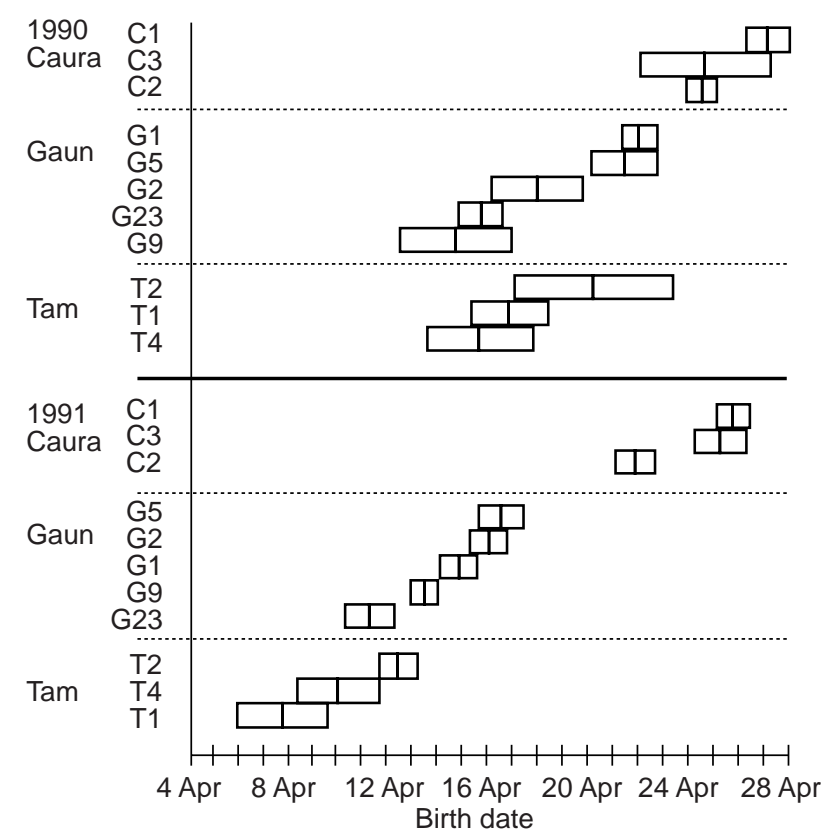

Fig. 1. Mean birth dates (centre vertical line) \pm standard error for each group (i.e. C1, C3, etc.) in Caura, Guanapo (Guan), and Tamana (Tam) caves in 1990 and 1991. In each year, groups are sorted by ascending mean birth date.

(mean $=19$ April \pm 0.58 days) than in 1991 (mean $=15$ April \pm 0.56 days; $F_{1,8}=12.09, \quad P=0.008 ; \quad$ Fig. 1 ). Despite this shift between years, the pattern of differences in mean birth dates remained the same among the caves. Pups in both Tamana and Guanapo Caves were born significantly earlier (Tamana mean $=13$ April \pm 0.78 days; Fisher's PLSD post-hoc test: $P<0.001$; Guanapo mean $=16$ April \pm 0.47 days, $P=0.002$ ) than pups in Caura Cave, which lies on the drier west side of the island (mean $=24$ April \pm 0.45 days). Birth dates in Tamana and Guanapo Caves did not differ significantly. Variance component estimates indicate that cave accounted for $39 \%$ of the variation in birth dates.

The pattern of birth dates recorded for Guanapo Cave in 1995 and 1997 yielded results comparable to those obtained from the analysis of the 1990 and 1991 records, despite the different methods used for obtaining the data. In $1995,96.8 \%$ of 308 recorded births occurred between 1 and 30 April, as compared to $95.2 \%$ of 314 births in 1997. Each group produced 8-25 pups in both $1995($ mean $=15.4 \pm 1.1)$ and $1997($ mean $=15.7 \pm 1.0)$. Again, the overall mean birth date differed significantly between years, with 1995 parturitions occurring later in the year (mean $=15$ April \pm 0.35 days) than in 1997 $\left(\right.$ mean $=13$ April \pm 0.45 days; $F_{1,494}=13.76, P=0.002$; Fig. 2).

In addition to synchrony within caves, births were synchronized within groups in 1990 and 1991, as evidenced by significantly more variation in birth date between than within groups in a cave (Table 1). Group differences accounted for $14 \%$ of the variance in birth

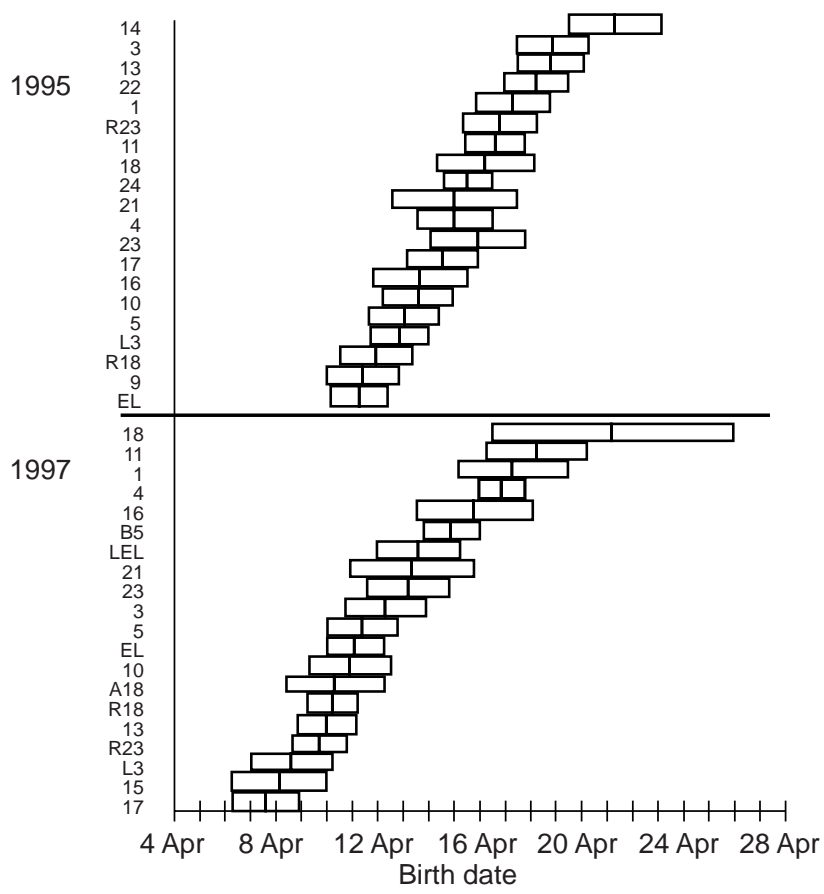

Fig. 2. Mean birth dates (centre vertical line) \pm standard error for each of the groups in Guanapo Cave in 1995 and 1997. In each year groups are sorted by ascending mean birth date.

dates in 1990 and 1991. Group differences in birth dates were also detected in $1995\left(F_{19,281}=3.59, P<0.0001\right)$ and in $1997\left(F_{19,294}=4.01, P<0.0001\right)$. Across 1995 and 1997 , the mean range of birth dates within groups was $18.6 \pm 0.9$ days.

After correction for differences between caves, the mean birth dates for each group in 1990 and 1991 were positively correlated $(r=0.64$, d.f. $=9, \quad P=0.032)$. However, we did not find a significant correlation between 1995 and 1997 in mean group birth dates $(r=0.30$, d.f. $=14, P=0.26)$, indicating that high withingroup synchrony cannot always be attributed to a preservation of relative birth order among the groups in a cave.

Within Guanapo Cave, members of one group seemed not to influence reproductive timing in a neighbouring group despite roosting side-by-side in common solution depressions. The mean difference in birth dates between the four pairs of adjacent groups (4.2 \pm 1.0 days) did not differ significantly from the mean predicted by randomization $(3.2 \pm 1.1$ days; $P=0.36)$.

Table 1. Source table for ANOVA testing year (1990 vs 1991), cave, and group within cave effects

\begin{tabular}{lrrrrl}
\hline Source & d.f. & Mean square & \multicolumn{1}{l}{$P$} & Error term \\
\hline Year & 1 & 1295.65 & 12.09 & 0.0084 & Group (cave) \\
Cave & 2 & 2067.81 & 19.29 & 0.0009 & Group (cave) \\
Group (cave) & 8 & 107.19 & 5.74 & $<0.0001$ & Residual \\
Residual & 223 & 18.68 & & & \\
\hline
\end{tabular}




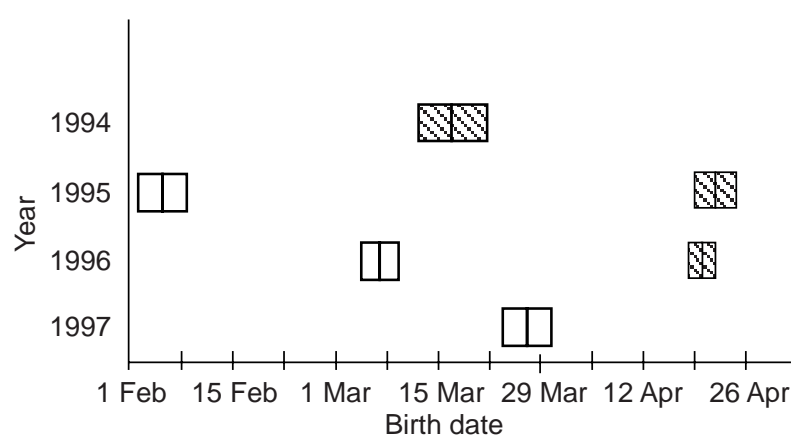

Fig. 3. Mean birth dates (centre vertical line) \pm standard error in each year for captive groups 1 (\$) and $2(\square)$. Note that birth data are absent for group 2 in 1994 and for group 1 in 1997.

\section{Group synchrony in captivity}

In each of the two captive groups, the first pups conceived in captivity were not born as synchronously as their wild counterparts. In Guanapo Cave, the mean standard deviation of birth dates within groups was $5.5 \pm 0.3$ days in 1995 and $5.7 \pm 0.3$ days in 1997. At the National Zoo, the standard deviations were 12.5 days for group 1 in $1994(Z=5.98$, d.f. $=7, P<0.001)$ and 10.3 days for group 2 in $1995(Z=4.15$, d.f. $=9$, $P<0.001$; Fig.3). The standard deviation in group 1 births dropped to 4.6 days in 1996. However, the variability in group 2 birth dates fluctuated over three captive birth seasons, starting at 10.3 in 1995, dropping to 8.0 in 1996, and reaching 11.6 in 1997. Across years, the mean birth range was $30.0 \pm 3.8$ days in group 1 and $29.3 \pm 7.8$ days in group 2 .

Conceptions among the group 2 females seemed to be delayed following capture and the introduction of a new male. First births from captive conceptions did not begin until January of 1995 (mean $=5$ February \pm 3.3 days), $>9$ months after the last group 1 birth of 1994 . Surprisingly, the timing of reproduction in both captive groups converged on the wild schedule, such that mean birth dates were 24 March 1996 for group 2 and 20 April 1997 for group 1.

Four of the five females transferred from group 1 to group 2 in 1996 gave birth in the next year. Although no births occurred in their natal group in 1997 for direct comparison because the male had been vasectomized, the transferred females gave birth significantly earlier in 1997 (mean $=16$ March \pm 3.0 days) than did their natal group in 1996 (mean $=20$ April \pm 1.4 days), with no overlap in days. Parturition dates for the transferred females did not differ from those of their new group in 1997 (mean $=25$ March \pm 2.7 days), demonstrating that females can synchronize reproduction within a year of joining a new group. Interestingly, although 13 of 15 females in group 2 did not reproduce after April 1997, two females in group 2 evidently experienced a postpartum oestrus before the vasectomy of the group 2 male and gave birth only 6 months after their previous parturitions.

\section{DISCUSSION}

These results provide strong evidence that social cues substantially modify reproductive timing in greater spear-nosed bats, resulting in greater birth synchrony than can be attributed to environmental factors alone. Environmental influences accounted for a substantial amount of the variation in birth timing on Trinidad, as evidenced by a significant effect of cave location in 1990-91 and a significant effect of year for both $1990 v s$ 1991 and 1995 vs 1997. Our findings are consistent with a strong effect of rainfall patterns, which differ among cave locations and years, on the timing of bat reproduction. The bats in Guanapo and Tamana Caves give birth consistently earlier in the year than do those in Caura Cave, which receives $30 \mathrm{~cm}$ less rain per year (Singh, 1997). Rainfall, because of its impact on food abundance, seems to be primarily responsible for birth seasonality in many other tropical bat species (Racey, 1982; Cumming \& Bernard, 1997; Racey \& Entwistle, 2000).

In all 4 years, births were synchronous within groups, usually occurring within 19 days. Group mean birth dates correlated between 1990 and 1991 within caves, indicating a preservation of birth order among the groups. Perhaps some stable characteristic of the group, such as a relatively fixed reproductive sequence or differences in the foraging areas used by the different groups, may contribute to the disparity in mean birth dates between groups within caves. However, birth order among groups was not preserved between 1995 and 1997, suggesting that local environmental effects are unlikely to account completely for birth synchrony within groups in this period. Some other factors particular to the social group, plausibly social cues, probably help co-ordinate reproduction.

The timing of births in two captive groups provides further evidence for the influence of social cues on reproductive synchrony. The captive bats experienced no seasonal changes in environment (e.g. light cycle, temperature, and food), and although parturition dates were significantly more variable than in wild groups, the within-group variability in their births did not increase over 3 years. Similarly, Porter (1979) documented the persistence of reproductive synchrony through three birth seasons in a captive colony of another neotropical phyllostomid bat, the short-tailed fruit bat Carollia perspicillata, despite a lack of seasonal cues. In contrast, Laska (1990) observed that reproductive synchrony persisted for only 1 year in captive short-tailed fruit bats without exposure to seasonal cues, and in the subsequent 2 years the number of births per year increased from two to three for many females and reproductive synchrony waned.

In the present study, because the captive reproductive male in each group was vasectomized a few months after the third birth season, we cannot assess whether birth synchrony in greater spear-nosed bats might disintegrate over a longer period of captivity. The occurrence of two births in group 2 only 6 months after the mothers 
gave birth previously is comparable to greater spearnosed bat reproductive patterns in Colombia and Venezuela (Wilson, 1979). Under a more prolonged period of captive reproduction, the reproductive rate in the colony might have increased as it did in Laska's (1990) colony of short-tailed fruit bats. None the less, birth synchrony in group 2 did not dissipate despite a 31-day shift in the mean birth date between the first 2 years and an added 20-day shift between the second and third years. The mean timing of births in group 1 shifted 36 days between the first and second years and by the third year, in which the mean birth date shifted 2 days earlier, birth dates became as synchronized as the wild births.

Furthermore, females transferred between the groups subsequently gave birth in synchrony with the new group and out of synchrony with their original group. This change in birth timing cannot be explained by the temperature differences in housing, because the females that were transferred to the slightly cooler room gave birth earlier in the year than their original group-mates, whereas consequential temperature reductions slow reproduction in bats (Ransome \& McOwat, 1994; Racey \& Entwistle, 2000). Neither seasonal environmental cues nor endogenous circannual cycles are sufficient to explain both the maintenance and incorporation of birth synchrony by new members we observed in captive greater spear-nosed bats.

In contrast to the mechanisms of reproductive synchrony reported for rats (McClintock, 1978), hamsters (Handelmann, Ravizza \& Ray, 1980), and humans (McClintock, 1971), airborne or other passively exchanged chemical cues seem unlikely to drive synchrony in these bats. Pairs of groups roosting in the same solution depression, close enough that members of different groups regularly shared physical contact with one another, were no more similar in their birth dates than randomly chosen groups. If females do influence the reproductive timing of their group-mates, interactions that exclude females in neighbouring groups are likely to be involved. We have observed females grooming one another with their mouths, which provides a potential mechanism for transferring nonvolatile chemical cues in the fur or excretions to the vomeronasal organ (Mann, 1961; Thompson, 1995).

Alternatively, chemical or tactile cues from the single male in each social group might co-ordinate reproduction among females. James (1977) presented evidence that greater spear-nosed bat females ovulate spontaneously in the absence of males. None the less, sometimes odours from male mammals may synchronize reproduction in spontaneously ovulating females, including humans (Vandenbergh, 1994). Male greater spear-nosed bats possess an enlarged, secretory sternal gland (James, 1977), which reproductive males rub onto the backs of females in their groups (pers. obs.). Reproductive males do not transfer between female groups, but remain with one group from a few months to 4 years or more (McCracken \& Bradbury, 1981; McCracken, 1987), which could account for short-term stability and long-term change in birth order among bat groups. Rasweiler (1975) suggested that males of another phyllostomid bat, the Mexican long-tongued bat Glossophaga sorcina, may produce chemical cues that influence the timing of female reproduction. Direct contact with male urine helps activate ovarian cyclicity in prairie vole Microtus ochrogaster and pine vole M. pinetorum females (Carter et al., 1987; Lepri \& Wysocki, 1987).

We cannot yet determine at what point reproduction becomes synchronized among female greater spearnosed bat group-mates. Bats possess a variety of mechanisms that can vary the timing of reproductive events, which may serve to synchronize reproduction in some tropical species (Bernard \& Cumming, 1997; Heideman \& Powell, 1998; Racey \& Entwistle, 2000). Females of some bat species store sperm for as long as 7 months after copulation before fertilization occurs and/or delay implantation of the zygote, although neither of these strategies has yet been confirmed in a phyllostomid bat (Racey, 1982; Racey \& Entwistle, 2000). The rate of embryonic development can change depending upon temperature and maternal nutrition in temperate-zone bats (Racey \& Swift, 1981; Bernard, 1994; Racey \& Entwistle, 2000). In the tropics as well as in temperate and subtropical zones, some bats demonstrate an obligate post-implantation delay in embryonic growth, including at least four phyllostomid bats: the short-tailed fruit bat, the Jamaican fruit bat Artibeus jamaicensis, the Mexican big-eared bat Macrotus waterhousii and the California leaf-nosed bat M. californicus (Jerrett, 1979; Racey, 1982; Rasweiler \& Badwaik, 1997; Racey \& Entwistle, 2000).

James (1977) killed adult female greater spear-nosed bats at various reproductive stages, both pre- and postconception, and did not find evidence of sperm storage or any delay in implantation or gestation. The embryo and corpus luteum grew in size continuously through pregnancy, whereas minimal growth in the size and activity of the corpus luteum seems to accompany delays in implantation and post-implantation gestation (e.g. Jamaican fruit bat, Fleming, 1971; pipistrelle bat Pipistrellus pipistrellus, Racey \& Swift, 1981; Schreibers' long-fingered bat Miniopterus schreibersii, Kimura, Takeda \& Uchida, 1987; Crichton, Seamark \& Krutzsch, 1989). The 5-month gestation in greater spearnosed bats (James, 1977) is normal for a large (80 g), non-hibernating bat (Racey, 1973, 1982) and does not suggest a post-conception delay in reproduction. None the less, brief delays may be difficult to detect, and it is possible that females postpone parturition or reduce gestation by a few days to co-ordinate birth with their group-mates (Berger, 1992).

Studies of mammalian reproductive patterns provide increasing evidence for a variety of selective advantages offspring may gain when they are born in synchrony with their neighbours (Boinski, 1987; Rutberg, 1987). Socially-mediated birth synchrony in mammals is typically observed in large groups of female kin or temporary associations among non-kin females who 
help to protect or nurse young (Rood, 1980; Boinski, 1987; Rutberg, 1987; Ims, 1990; Mennella et al., 1990). Young born in synchrony with others in the social group may be more likely to receive allomaternal care (Boinski, 1987; Ims, 1990), or parasitize other mothers in the group (Packer, Lewis \& Pusey, 1992). Commonly, one or more adult female Phyllostomus hastatus from each group remain in the roost cavity huddled with the pups while the other females forage, potentially providing warmth and protection. We have occasionally observed females nursing non-kin pups, sometimes simultaneously with their own (T. A. Porter \& G. S. Wilkinson, pers. obs.). Wilkinson \& Boughman (1998) provided evidence that greater spear-nosed bat females tend to forage socially with group-mates. Another benefit of reproductive synchrony is that co-operative foraging may allow the transfer of information on food sources, which is especially vital during lactation (Ims, 1990; Wilkinson \& Boughman, 1998). Synchronous reproduction could, therefore, help explain the high degree of group fidelity exhibited by female greater spear-nosed bats (McCracken \& Bradbury, 1981; Wilkinson, 1987).

\section{Acknowledgments}

We are especially grateful to Janette Boughman, who shared banding data, arranged for the capture, transport, and care of captive bats and provided advice and comments on the typescript. April Stern shared banding data and advice. Vishnu Maharaj generously allowed us access to Guanapo Cave. We thank Peter Miller for data collection and animal care at the National Zoological Park (NZP), two anonymous reviewers for their thoughtful suggestions, and Baldeo Ramlal, Andrew Scherrer, Diane Lill, Mukesh Ramdass, Susan Davidson, Christine Archer, Kathleen Gobush, Carolynn Smith, Shyril O'Steen, Alistair Cullum and Greg Cleven for field assistance. Research support was provided by PHS 5 F32 HD07928-03, NSF IBN9209401, the Graduate Research Board of the University of Maryland and the Department of Zoological Research, NZP. The Department of Forestry and Wildlife of Trinidad and Tobago granted us permission to carry out our field research. This work was conducted with approval by the University of Maryland and National Zoological Park Animal Care and Use Committees.

\section{REFERENCES}

Berger, J. (1992). Facilitation of reproductive synchrony by gestation adjustment in gregarious mammals: a new hypothesis. Ecology 73: 323-329.

Bernard, R. T. F. (1994). Reproductive synchrony and annual variation in foetal growth rate in the long-fingered bat (Miniopterus schreibersii). J. Zool. (Lond.) 232: 485-490.

Bernard, R. T. F. \& Cumming, G. S. (1997). African bats: Evolution of reproductive patterns and delays. Q. Rev. Biol. 72: 253-274.
Boinski, S. (1987). Birth synchrony in squirrel monkeys (Saimiri oerstedi). Behav. Ecol. Sociobiol. 21: 393-400.

Boughman, J. W. (1998). Vocal learning by greater spear-nosed bats. Proc. R. Soc. Lond. B Biol. Sci. 265: 227-233.

Bradbury, J. W. (1979). Behavioural aspects of reproduction in Chiroptera. J. Reprod. Fertil. 56: 431-438.

Carter, C. S., Witt, D. M., Schneider, J., Harris, Z. L. \& Volkening, D. (1987). Male stimuli are necessary for female sexual behavior and uterine growth in prairie voles (Microtus ochrogaster). Horm. Behav. 21: 74-82.

Crichton, E. G., Seamark, R. F. \& Krutzsch, P. H. (1989). The status of the corpus luteum during pregnancy in Miniopterus schreibersii (Chiroptera: Vespertilionidae) with emphasis on its role in developmental delay. Cell Tissue Res. 258: 183-201.

Cumming, G. S. \& Bernard, R. T. F. (1997). Rainfall, food abundance and timing of parturition in African bats. Oecologia (Berl.) 111: 309-317.

Fleming, T. H. (1971). Artibeus jamaicensis: delayed embryonic development in a neotropical bat. Science 171: 402-404.

Handelmann, G., Ravizza, R. \& Ray, W. J. (1980). Social dominance determines estrous entrainment among female hamsters. Horm. Behav. 14: 107-115.

Heideman, P. D. (1995). Synchrony and seasonality of reproduction in tropical bats. Symp. zool. Soc. Lond. No. 67: 151-165.

Heideman, P. D. (2000). Environmental regulation of reproduction. In The reproductive biology of bats: 469-499. Crichton, E. G. \& Krutzsch, P. H. (Eds). London: Academic Press.

Heideman, P. D. \& Powell, K. S. (1998). Age-specific reproductive strategies and delayed embryonic development in an old world fruit bat, Ptenochirus jagori. J. Mammal. 79: 295-311.

Ims, R. A. (1990). The ecology and evolution of reproductive synchrony. Trends Ecol. Evol. 5: 135-140.

James, C. J. W. (1977). Studies on reproduction in the bat Phyllostomus hastatus in Trinidad, WI. University of the West Indies, St Augustine, Trinidad, WI.

Jerrett, D. P. (1979). Female reproductive patterns in nonhibernating bats. J. Reprod. Fertil. 56: 369-378.

Kimura, K., Takeda, A. \& Uchida, T. A. (1987). Changes in progesterone concentrations in the Japanese long-fingered bat, Miniopterus schreibersii fuliginosus. J. Reprod. Fertil. 80: 59-63.

Laska, M. (1990). Gestation period and between birth intervals in Carollia perspicillata (Phyllostomatidae, Chiroptera). J. Zool. (Lond.) 222: 697-702.

Lepri, J. J. \& Wysocki, C. J. (1987). Removal of the vomeronasal organ disrupts the activation of reproduction in female voles. Physiol. Behav. 40: 349-355.

Mann, G. (1961). Bulbus olfactorius accessorius in Chiroptera. J. Comp. Neurol. 116: 135-141.

McClintock, M. K. (1971). Menstrual synchrony and suppression. Nature (Lond.) 229: 244-245.

McClintock, M. K. (1978). Estrous synchrony and its mediation by airborne chemical communication (Rattus norvegicus). Horm. Behav. 10: 264-276.

McCracken, G. F. (1987). Genetic structure of bat social groups. In Recent advances in the study of bats: 281-298. Racey, P. A., Fenton, M. B. \& Rayner, J. M. (Eds). Cambridge: Cambridge University Press.

McCracken, G. F. \& Bradbury, J. W. (1981). Social organization and kinship in the polygynous bat Phyllostomus hastatus. Behav. Ecol. Sociobiol. 8: 11-34.

Mennella, J. A., Blumberg, M. S., McClintock, M. K. \& Moltz, H. (1990). Inter-litter competition and communal nursing among Norway rats: advantages of birth synchrony. Behav. Ecol. Sociobiol. 27: 183-190.

Packer, C., Lewis, S. \& Pusey, A. (1992). A comparative analysis of non-offspring nursing. Anim. Behav. 43: 265-281.

Porter, F. L. (1979). Social behavior in the leaf-nosed bat, Carollia perspicillata. I. Social organization. Z. Tierpsychol. 49: 406-417. 
Racey, P. A. (1973). Environmental factors affecting the length of gestation in heterothermic bats. J. Reprod. Fert. Suppl. 19: 175-189.

Racey, P. A. (1982). Ecology of bat reproduction. In The ecology of bats: 57-104. Kunz, T. H. (Ed.). New York: Plenum Press.

Racey, P. A. \& Entwistle, A. C. (2000). Life history and reproductive strategies of bats: 363-414. In Reproductive biology of bats: Crichton, E. G. \& Krutzsch, P. H. (Eds). London: Academic Press.

Racey, P. A. \& Swift, S. M. (1981). Variations in gestation length in a colony of pipistrelle bats (Pipistrellus pipistrellus) from year to year. J. Reprod. Fertil. 61: 123-129.

Ransome, R. D. \& McOwat, T. P. (1994). Birth timing and population changes in greater horseshoe bat colonies (Rhinolophus ferrumequinum) are synchronized by climactic temperature. Zool. J. Linn. Soc. 112: 337-351.

Rasweiler, J. J., IV (1975). Maintaining and breeding neotropical frugivorous, nectivorous and pollenivorous bats. Int. Zoo Yearb. 15: 18-30.

Rasweiler, J. J., IV \& Badwaik, N. K. (1997). Delayed development in the short-tailed fruit bat, Carollia perspicillata. J. Reprod. Fertil. 109: 7-20.

Rood, J. P. (1980). Mating relationships and breeding suppression in the dwarf mongoose. Anim. Behav. 28: 143-150.

Rutberg, A. T. (1987). Adaptive hypotheses of birth synchrony in ruminants: an interspecific test. Am. Nat. 130: 692-710.
Singh, B. (1997). Climate changes in the greater and southern Caribbean. Int. J. Climatol. 17: 1093-1114.

Stern, A. A. \& Kunz, T. H. (1998). Intraspecific variation in postnatal growth in the greater spear-nosed bat. J. Mammal. 79: 755-763.

Thompson, K. V. (1995). Flehmen and birth synchrony among female sable antelope, Hippotragus niger. Anim. Behav. 50: 475-484.

Vandenbergh, J. G. (1994). Pheromones and mammalian reproduction. In The physiology of reproduction: 343-359. Knobil, E. \& Neill, J. D. (Eds). New York: Raven Press.

Wilkinson, G. S. (1987). Altruism and cooperation in bats. In Recent advances in the study of bats: 299-323. Racey, P. A., Fenton, M. B. \& Rayner, J. M. V. (Eds). Cambridge: Cambridge University Press.

Wilkinson, G. S. \& Boughman, J. W. (1998). Social calls coordinate foraging in greater spear-nosed bats. Anim. Behav. 55: 337-350.

Wilson, D. E. (1979). Reproductive patterns. In Biology of bats of the New World family Phyllostomatidae. Part III: 317-378. Baker, R. J., Knox Jones, J. Jr \& Carter, D. C. (Eds). Lubbock: Texas Tech Press.

Wimsatt, W. A. \& Trapido, H. (1952). Reproduction and the female reproductive cycle in the tropical American vampire bat, Desmodus rotundus murinus. Am. J. Anat. 91: 415-446. 